\title{
Energy consumption in the manufacture of metal powders by vibratory disintegration methods
}

\author{
Alexander Samukov ${ }^{1}$, Margarita Cherkasova ${ }^{2}$, Nadezhda Rzhankova ${ }^{3}$, Sergey Dmitriev ${ }^{4}$ \\ REC "Mekhanobr-Tekhnika”, Saint Petersburg, Russia \\ ${ }^{4}$ Corresponding author \\ E-mail: ${ }^{1}$ samykov_ad@mtspb.com, ${ }^{2}$ cherkasova_mv@mtspb.com, ${ }^{3}$ rzhankova_nb@mtspb.com, \\ ${ }^{4}$ dmitriev_sv@mtspb.com
}

Received 5 June 2020; accepted 17 June 2020

DOI https://doi.org/10.21595/vp.2020.21544

Check for updates

Copyright (C) 2020 Alexander Samukov, et al. This is an open access article distributed under the Creative Commons Attribution License, which permits unrestricted use, distribution, and reproduction in any medium, provided the original work is properly cited.

\begin{abstract}
The results obtained in comparative vibratory disintegration studies of alloy metal chips are presented. The specific performance and energy consumption indicators are established. The paper assesses the influence of the level of vibration exposure on the material crushed in a KID vibratory crusher and on the efficiency of its subsequent grinding in a vibrating mill.
\end{abstract}

Keywords: additive manufacturing, metal powders, metal chips crushing, KID vibratory crusher, metal chips grinding, drum mill grinding of metals, vibrating mill grinding of metals, vibration exposure, vibration fracturing mechanics.

\section{Introduction}

Powder metallurgy and especially 3D printing/additive manufacturing are rapidly growing, which, in turn, requires expanding the resource base and increasing the output of high-grade dispersed powders, while reducing their production costs [1,2].

When searching for additional sources of metal, secondary raw materials are notable. For example, in the Russian metalworking industry, millions of tons of metal chips are generated annually, of which about a quarter are made of alloy steel and non-ferrous metals [3, 4].

Metal powders are mainly obtained by molten metal dispersion and metal recovery from oxides and salts. In the smelting process used for secondary raw materials, up to $20 \%$ of alloying additives burn out and are lost irretrievably. Metal chip utilization without remelting, with the use of mechanical grinding to obtain metal powders, may have a significant economic effect due to the recovery of such valuable alloying additives and reduced power consumption $[5,6]$.

A ball mill is the most common device suitable for metal chip grinding. Grinding is ensured by impacts, abrasion, and crushing: with the drum rotation, the grinding balls are raised by friction to a certain height and then fracture the material by freely falling and rolling. However, this device has low grinding efficiency for metals, while the energy intensity of the process is only slightly lower than in pyroprocessing.

A sustainable disintegration technology requires such conditions that would contribute to the development of microcracks, which are in most cases already present in the chips. The concentrated application of impact loads in a ball mill at random values and locations, however, does not contribute to the development of microcracks and is the main reason for the high energy intensity and low processing efficiency of such devices. At the same time, the range in which the energy efficiency of such mills may be improved by intensifying the effects of the grinding medium on the material is structurally limited by the so-called "critical" rotation speed, at which the centrifugal forces start pressing the grinding medium to the drum.

This calls for the development of a more advanced technology for the manufacture of metal powders, that would use energy-efficient equipment. A solution for this problem will pave the way to a wider range of more cost-efficient raw materials for the rapidly developing additive manufacturing sector.

For these purposes, devices are required in which feed material particles would be exposed to a three-dimensional stress state, instead of uniaxial stresses. This becomes possible when the 
material layer is cyclically compacted in the working area and the working surfaces and the surfaces of grinding media act on the particle through neighboring particles, while the accelerations are many times greater than the acceleration of gravity, which is fundamentally possible in traditional ball mills.

In terms of their design features and the dynamics of their impact on the material being crushed, KID vibratory crushers [7] and vibrating mills [8] are deemed most suitable for providing the above conditions.

\section{Experiment and results}

In order to evaluate the effectiveness of using vibratory disintegration technologies in the manufacture of metal powders for powder metallurgy and additive manufacturing, comparative vibratory disintegration studies were carried out using metal chips.

The feed material for the studies was represented by alloy metal machining chips with the nickel content of $77 \%$, without the metal-working oil, generated in mechanical milling of parts with the size of less than $30 \mathrm{~mm}$.

Laboratory and pilot-scale crushing and grinding equipment developed and manufactured by Mekhanobr-Tekhnika REC was used in the studies.

The multi-stage mechanical processing of the material was implemented by primary crushing of the metal chips in an MD $3 \times 0.65$ hammer mill (with the $\varnothing 5$ and $\varnothing 2.5 \mathrm{~mm}$ discharge mesh), by secondary crushing in a KID-300 vibratory crusher, and by subsequent grinding in a vibrating mill.

In the studies, the influence of the level of vibration exposure on the material crushed in a KID-300 crusher and on the efficiency of its further grinding in a vibrating mill was assessed. The level of vibration exposure was measured by the number of material passes through the crusher. The vibration exposure options studied included two, five, and ten passes through the KID crusher, as well as options with zero exposure. The grinding efficiency was estimated on the basis of specific performance indicators of the vibrating mill in the particle size classes of less than 125 and $74 \mu \mathrm{m}$, as well as by the specific energy consumption required to obtain these size classes.

The results of particle-size analysis for the feed material and for the hammer mill (MD) crushing products are presented in Fig. 1.

The weighted average particle size of the crushing products of the hammer mill was 1.82 and $1.25 \mathrm{~mm}$ with the discharge mesh size was 5 and $2.5 \mathrm{~mm}$, respectively.

Vibratory crushing was carried out using a KID-300 crusher, with the setting of $2 \mathrm{~mm}$. For the setups with two and ten material passes, the material feed to the crusher was batched to form a monolayer between the crushing surfaces. In the experiment with five material passes, the material sample was completely loaded into the receiving hopper of the crusher, ensuring its choke feed and crushing in a material layer. The particle-size curves for the KID-300 crushing products are shown in Fig. 2.

Based on the particle-size characteristics obtained for the crushing products, the weighted average particle sizes of $1.21,0.93$, and $1.42 \mathrm{~mm}$ were calculated for the number of passes through the KID vibratory crusher of two, five, and ten, respectively.

Vibratory grinding was carried out in a vibrating mill, designed as an eight-chamber continuous-discharge roller mill. The chambers were located radially from the drive axis and interconnected by channels in the heads of the cylindrical body in such a way that the feed material loaded into the receiving hopper was divided into two streams and each of the streams would pass four chambers in succession to be then discharged from the mill. The vibrating mill body was located on rubber shock absorbers; the vibrations were communicated through an unbalanced vibrator driven by an electric motor. Rollers were used as the grinding media. The oscillation frequency in the studies was $19.5 \mathrm{~Hz}$, with the oscillation amplitude of $6.7 \mathrm{~mm}$. 


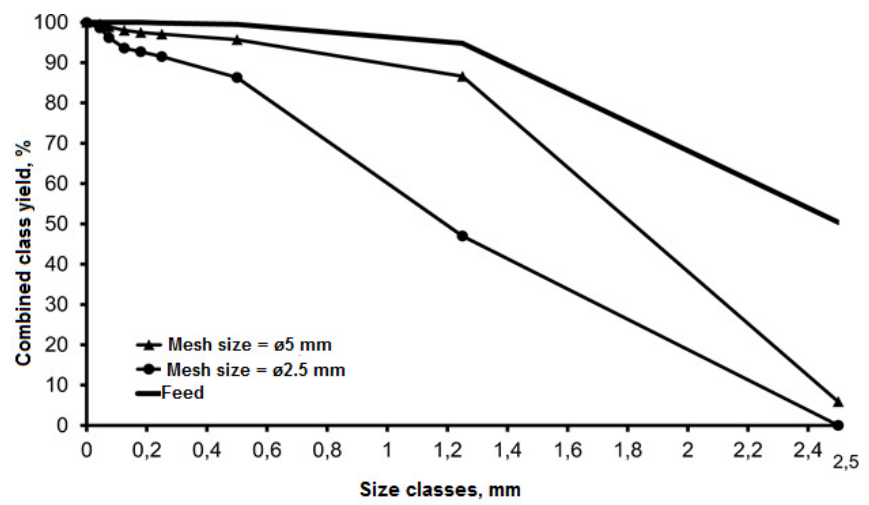

Fig. 1. Feed material and hammer mill crushing products

Four grinding cycles were conducted in each of the experiments using the vibrating mill. The feed material was loaded in batches of 600-800 grams every 10 minutes. With the same frequency (10 $\mathrm{min}$.), the direction of rotation of the unbalanced drive was reversed to ensure uniform material discharge from the right and left groups of mill chambers. After each stop to change the rotation direction of the vibrating drive, the material discharged was weighed to monitor the weight of the remaining material. The grinding process was stopped when over $90 \%$ of the ground product had been discharged from the vibrating mill. The remaining ground material was forced out using compressed air. The grinding product was subjected to particle-size analysis. The finished product with the particle sizes of less than $125 \mu \mathrm{m}$ was separated from the material discharged; the product of over $125 \mu \mathrm{m}$ was used as the feed for the subsequent grinding cycle. The power consumption and the grinding time were recorded for each grinding cycle.

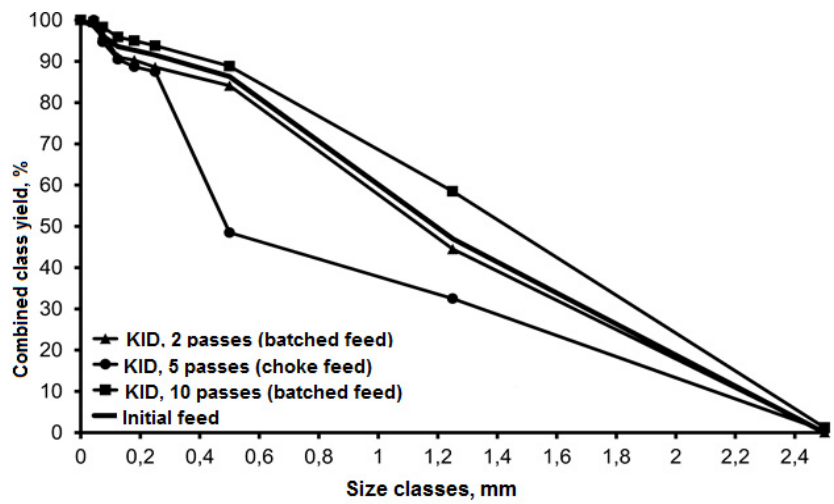

Fig. 2. Particle-size composition of KID crushing products

For comparison with the process efficiency indicators of the traditional technology, the material obtained in primary hammer mill crushing (with the mesh size of $\varnothing 2.5 \mathrm{~mm}$ ) was ground in an MSL-14K batch-operated cantilever-type laboratory ball mill with the drum working volume of 14 liters. The ball charge was $40 \%$; the ball diameter was 40,25 , and $20 \mathrm{~mm}$, with the percentage ratio of 50:34:16, respectively. The mill rotation rate was $71 \mathrm{rpm}$ ( $76 \%$ of the critical value).

For a comparative assessment of the grinding efficiency, based on the results obtained during the experiments, the specific performance indicators of the vibrating mill and the ball mill were calculated for the particle sizes of less than 125 and $74 \mu \mathrm{m}$, as well as the total specific energy consumption required to obtained these classes (including the energy consumption for the crushing process). The specific indicators are presented in Table 1 and in Figs. 3 and 4. 
Table 1. Specific crushing and grinding efficiency indicators

\begin{tabular}{|c|c|c|c|c|c|c|}
\hline \multirow[b]{2}{*}{ Parameters } & \multicolumn{6}{|c|}{ Equipment process flows compared } \\
\hline & $\begin{array}{l}\text { MD (mesh } \\
\text { size of } \\
5 \mathrm{~mm})+ \\
\text { Vibrating } \\
\text { mill }\end{array}$ & $\begin{array}{l}\text { MD (mesh } \\
\text { size of } \\
2.5 \mathrm{~mm})+ \\
\text { Vibrating } \\
\text { mill }\end{array}$ & $\begin{array}{c}\text { MD (mesh } \\
\text { size of } \\
2.5 \mathrm{~mm})+ \\
\text { KID } \\
(2 \text { passes) }+ \\
\text { Vibrating } \\
\text { mill } \\
\end{array}$ & $\begin{array}{c}\text { MD (mesh } \\
\text { size of } \\
2.5 \mathrm{~mm})+ \\
\text { KID } \\
\text { (5 passes) }+ \\
\text { Vibrating } \\
\text { mill } \\
\end{array}$ & $\begin{array}{c}\text { MD (mesh } \\
\text { size of } \\
2.5 \mathrm{~mm})+ \\
\text { KID } \\
\text { (10 passes) }+ \\
\text { Vibrating } \\
\text { mill } \\
\end{array}$ & $\begin{array}{l}\text { MD (mesh } \\
\text { size of } \\
2.5 \mathrm{~mm})+ \\
\text { Ball mill }\end{array}$ \\
\hline 1 & 2 & 3 & 4 & 5 & 6 & 7 \\
\hline $\begin{array}{l}\text { Specific vibrating } \\
\text { mill performance } \\
\text { (ball mill), } \mathrm{kg} / \mathrm{m}^{3} \cdot \mathrm{h}\end{array}$ & 80.1 & 97.1 & 95.6 & 108.0 & 103.5 & 5.0 \\
\hline $\begin{array}{c}\text { Specific vibrating } \\
\text { mill performance } \\
\text { (ball mill) for the } \\
\text { class of }-0.125 \mathrm{~mm} \text {, } \\
\mathrm{kg} / \mathrm{m}^{3} \cdot \mathrm{h}\end{array}$ & 44.0 & 50.1 & 60.5 & 63.0 & 58.1 & 2.9 \\
\hline $\begin{array}{l}\text { Specific vibrating } \\
\text { mill performance } \\
\text { (ball mill) for the } \\
\text { class of }-0.074 \mathrm{~mm} \text {, } \\
\mathrm{kg} / \mathrm{m}^{3} \cdot \mathrm{h}\end{array}$ & 20.9 & 23.2 & 28.4 & 35.6 & 27.7 & 1.9 \\
\hline $\begin{array}{l}\text { Specific energy } \\
\text { consumption for } \\
\text { crushing (hammer } \\
\text { mill/KID), } \mathrm{kW} \cdot \mathrm{h} / \mathrm{kg}\end{array}$ & $\begin{array}{c}0.04 \\
-\end{array}$ & $\begin{array}{c}0.14 \\
-\end{array}$ & $\begin{array}{l}0.14 \\
0.07\end{array}$ & $\begin{array}{l}0.14 \\
0.07\end{array}$ & $\begin{array}{l}0.14 \\
0.57\end{array}$ & $\begin{array}{c}0.14 \\
-\end{array}$ \\
\hline $\begin{array}{l}\text { Specific energy } \\
\text { consumption for } \\
\text { grinding, } \mathrm{kW} \cdot \mathrm{h} / \mathrm{kg}\end{array}$ & 3.02 & 2.54 & 2.84 & 2.60 & 2.44 & 4.16 \\
\hline $\begin{array}{l}\text { Total specific energy } \\
\text { consumption to } \\
\text { obtain the class of } \\
-0.125 \mathrm{~mm}, \mathrm{~kW} \cdot \mathrm{h} / \mathrm{kg}\end{array}$ & 5.5 & 5.1 & 4.7 & 4.7 & 5.1 & 7.5 \\
\hline $\begin{array}{l}\text { Total specific energy } \\
\text { consumption to } \\
\text { obtain the class of } \\
-0.074 \mathrm{~mm}, \mathrm{~kW} \cdot \mathrm{h} / \mathrm{kg}\end{array}$ & 11.6 & 10.8 & 9.8 & 8.1 & 9.8 & 11.1 \\
\hline
\end{tabular}

\section{Discussion}

The results of the vibratory disintegration comparative studies for metal chips allowed identifying the following patterns:

- Changes in the discharge mesh sizes from 5 to $2.5 \mathrm{~mm}$ may reduce the weighted average particle size by a factor of 1.5 , while the specific vibrating mill performance increases by $14 \%$ in the class of less than $125 \mu \mathrm{m}$ and by $11 \%$ in the class of less than $74 \mu \mathrm{m}$, and the specific energy consumption is reduced by $9 \%$ and $8 \%$, respectively.

- With the feed material equally prepared for grinding, the ball mill is significantly inferior to the vibrating mill in terms of the specific performance values as related to their working volumes. For the feed material, the specific performance of a vibrating mill is 19.4 times higher than that of a ball mill and is 17.5 and 12.5 times higher in the classes of 125 and $74 \mu \mathrm{m}$, respectively. Moreover, the coarser the size class, the more intensive its fracturing becomes in a vibrating mill, as compared to a ball mill. The electric power consumption for metal chip grinding in a vibrating mill was $2.54 \mathrm{~kW} \cdot \mathrm{h} / \mathrm{kg}$, which is 1.64 times lower than that for ball mill grinding $(4.16 \mathrm{~kW} \cdot \mathrm{h} / \mathrm{kg})$.

- The use of a KID vibratory crusher (depending on the intensity of exposure and the material 
feeding method) allowed increasing the specific vibrating mill performance by $18-29 \%$ in the class of less than $125 \mu \mathrm{m}$ and by $22-59 \%$ in the class of less than $74 \mu \mathrm{m}$. At the same time, the total specific energy consumption to obtain the end products with the particle sizes of less than 125 and $74 \mu \mathrm{m}$ was reduced by $6-7 \%$ and $8-22 \%$, respectively.

- The increase in vibrating mill grinding efficiency depends not only on the number of KID passes, but also on the material feeding method.

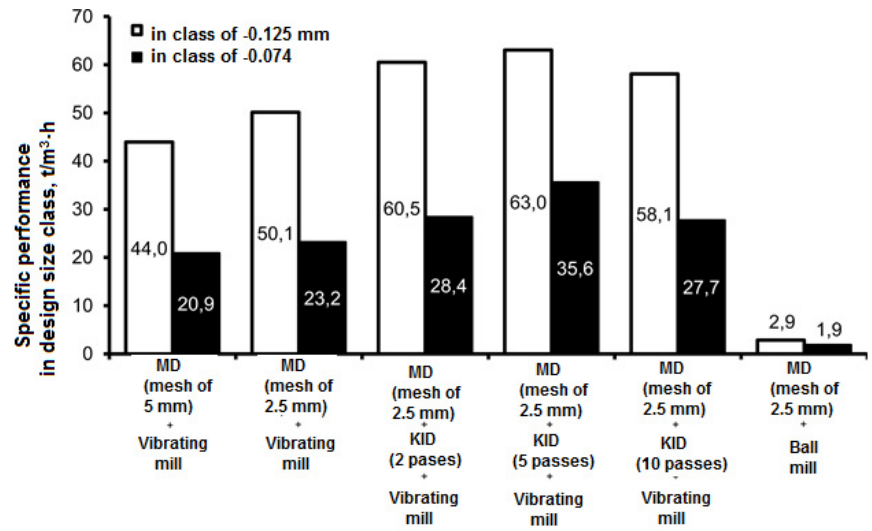

Fig. 3. Specific mill performance indicators by the particle size classes of less than 125 and $74 \mu \mathrm{m}$, depending on the process flow and equipment operation modes

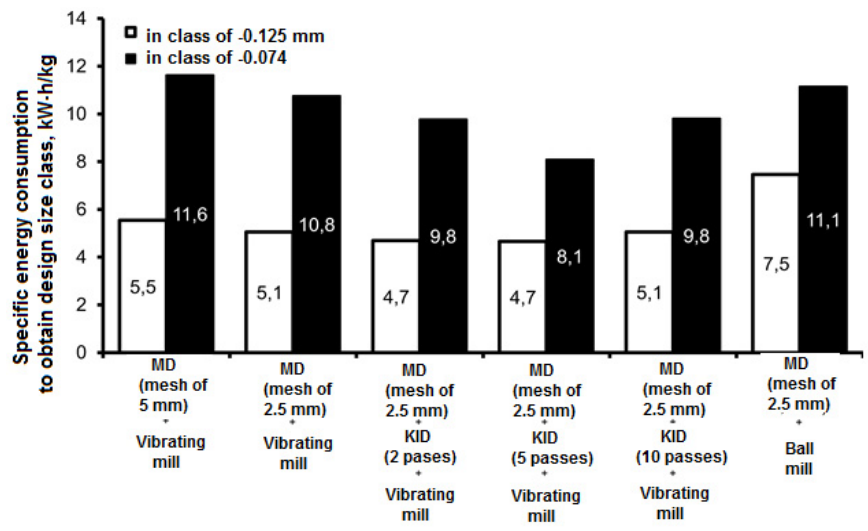

Fig. 4. Total specific energy consumption to obtain the particle size classes of less than 125 and $74 \mu \mathrm{m}$, depending on the process flow and equipment operation modes

With batched feeding and the formation of a material monolayer between the crushing surfaces, high levels of vibration exposure for the material (ten KID passes) lead to higher average-weighted sizes of the crushing product $(1.25$ to $1.42 \mathrm{~mm})$ due to intensive flattening of the particles. This results in lower grinding efficiency indicators as compared with low vibration exposure levels (two KID passes), with the specific performance of vibration grinding dropping by 6 and $3 \%$ for the classes of less than 125 and $74 \mu \mathrm{m}$, respectively, and energy consumption values growing by $6 \%$ for the classes of less than $125 \mu \mathrm{m}$.

The choke feed method of supplying the material into the receiving hopper of the crusher and ensuring vibratory crushing in a material layer proved to be significantly more efficient. At the medium vibration exposure level (five KID passes), the increase in specific performance as compared to monolayer crushing with two KID passes amounted to 5 and $34 \%$ for the classes of less than 125 and $74 \mu \mathrm{m}$, respectively. The decrease in the total specific energy consumption in this case was 1 and $14 \%$ for the classes of less than 125 and $74 \mu \mathrm{m}$, respectively. 


\section{Conclusions}

1) A novel approach to mechanical production of metal powders using vibratory equipment has been proposed and investigated.

2) It has been established that the use of smaller discharge mesh sizes $(2.5 \mathrm{~mm}$ instead of $5 \mathrm{~mm}$ ) reduces the size of the crushing product downstream of a high-speed rotary disintegrator, producing an overall positive effect. The increase in the specific performance of vibratory grinding observed for the classes of less than $125 \mu \mathrm{m}$ exceeds $10 \%$, with the energy consumption reduced by $8 \%$ or more.

3) The specific feed capacity of a vibrating mill exceeds that of a ball mill by a factor of 19.4 and is 17.5 and 12.5 times higher in the classes of less than 125 and $74 \mu \mathrm{m}$, respectively. The energy consumption when grinding metal chips in a vibrating mill is 1.64 times lower than that in a ball mill.

4) The use of a vibrating crusher in a multi-stage process flow renders a positive effect regardless of the level of vibration exposure of the material, as compared to process flows without KID crushers.

5) An increase in the level of vibration exposure in a KID crusher with batched material feeding and the formation of a monolayer between the crushing surfaces reduces the efficiency of downstream vibration grinding.

6) A higher efficiency has been established for the choke feed method of material supply to the receiving hopper of the crusher, ensuring vibratory crushing in the material layer, as compared with the batched feed with the formation of a monolayer. This feeding method requires a more in-depth study to assess the effects of the level of vibration exposure.

\section{Acknowledgements}

We are very grateful to the team of Peter the Great St. Petersburg Polytechnic University.

The study was carried out under the grant issued by the Russian Science Foundation (Project No. 17-79-30056).

\section{References}

[1] Herbert D. Perspectives of powder metallurgy in the 2020s. Advanced Engineering Forum, 2019.

[2] Herbert D. What will be the future of powder metallurgy? Powder Metallurgy Progress, Vol. 18, Issue 2018, 2, p. 70-79.

[3] Xueyang C., Lei Y., Wei Li, Zhiyuan W., Frank L. Newkirk J. Effect of powder particle size on the fabrication of Ti-6Al-4V using direct laser metal deposition from elemental powder mixture. Journal of Mechanics Engineering and Automation, Vol. 6, 2016, p. 348-355.

[4] Fullenwider B., Kiani P., Schoenung J. M., Ma K. From Recycled Machining Waste to Useful Powders for Metal Additive Manufacturing. Springer Briefs in Applied Sciences and Technology, 2019, p. 3-7.

[5] Francisco Paula Gómez Cuevas Metals Powders: Synthesis and Processing. Metals, Vol. 9, Issue 12, 2019, p. 1358.

[6] Popovich A., Sufiiarov V. Metal powder additive manufacturing. Intech Open, 2016, https://doi.org/10.5772/63337.

[7] Vaisberg L., Safronov A. Vibratory disintegration application in processing of different materials. Obogashchenie Rud (Mineral Processing Journal), Vol. 1, 2018, p. 3-11.

[8] Cherkasova M., Samukov A., Dmitriev S. Vibration technologies for producing metal powders. Vibroengineering Procedia, Vol. 25, 2019, p. 208-213. 